\title{
Thyroid Disorders in Pregnancy: Role of Routine Antenatal Thyroid Screening
}

\author{
Fatema Binta Islam, ' Lipika Ghosh, ${ }^{2}$ Nurun Nahar Khanam, ${ }^{3}$ A M Ashraful Anam ${ }^{4}$
}

\begin{abstract}
Background \& objective:Thyroid disorders are among the common endocrine problems during pregnancy with well-known adverse effects on both mother and fetus. Many of these adverse effects could be prevented or ameliorated by early detection and appropriate treatment of conditions, provided routine antenatal thyroid screening is done. Considering this view, the present study was aimed to find the prevalence of thyroid disorders and their spectrum in pregnancy in order to justify the necessity of routine antenatal thyroid screening.

Methods: This cross-sectional study was conducted in the Department of Obstetrics \& Gynaecology, Bangabandhu Sheikh Mujib Medical University (BSMMU), Dhaka over a period 1 year from July 2012 to June 2013 on pregnant women to screen for the thyroid disorders in pregnancy. Based on predefined eligibility criteria, a total of 246 pregnant women up to 36 weeks of gestation were consecutively included in the study. A short history with brief physical examination was done followed by collection of blood samples. Thyroid function was assessed by measuring serum levels of thyroid stimulating hormone (TSH). Serum free thyroxin (FT4) level was estimated in 71 cases, where TSH value was deranged. Trimester specific reference range of serum TSH was used to define hypothyroid, euthyroid and hyperthyroid cases. The suspected risk factors were then compared between abnormal and euthyroid groups to find their association with thyroid disorders.
\end{abstract}

Result: The results of the study showed that the overall prevalence of abnormal thyroid function status was $30.9 \%$ (hypothyroidism $29.7 \%$ and hyperthyroidism $1.2 \%$ ) based on normal range of serum TSH in different trimesters of pregnancy. Pregnant women with thyroid disorders were generally older than their euthyroid counterparts $(p=0.039)$. Hypothyroid state was fairly common with advancing gestation $\left(21.3 \%, 30.3 \%\right.$ and $34 \%$ in the $1^{\text {st }}, 2^{\text {nd }}$, and $3^{\text {rd }}$, trimesters respectively). Pregnant women with personal or family history of thyroid disease in the past exhibited a higher prevalence of abnormal thyroid function than those who did not have such history $(p=0.041$ and $p=0.044$ respectively). Past menstrual irregularity, past history of subfertility or abortion were significantly associated with thyroid disorders $(p=0.042, p=0.004$ and $p<0.001$ respectively). Presence of goitre $(21.1 \%)$ in current pregnancy also showed significant association with thyroid dysfunction $(p=0.001)$. The risk of developing abnormal thyroid function was observed to be $3.6(95 \% \mathrm{CI}=1.9-6.4)$ times higher in those who had at least one risk factor than those who did not have any risk factors $(p<0.001)$. However, a sizable portion $(27.6 \%)$ of pregnant women without any risk factors developed abnormal thyroid function.

Conclusion: The study concluded that one in every three women may have thyroid disorder during pregnancy, primarily hypothyroidism. Adopting risk factor-based screening for thyroid disorders in pregnancy, there is every chance that a substantial number of cases with thyroid dysfunction may be missed. Therefore, routine antenatal thyroid screening is recommended.

Key words: Thyroid disorders, pregnancy, antenatal thyroid screening etc.

\section{Authors' information:}

'Dr. Fatema Binta Islam, Assistant Professor, Ad-Din Women's Medical College, Boro Moghbazar, Dhaka.

${ }^{2}$ Dr. Lipika Ghosh, Assistant Professor, Colonel Malek Medical College, Manikgong

${ }^{3}$ Prof. Dr. Nurun Nahar Khanam, Professor, Bangabandhu Sheikh Mujib Medical University, Shahbag, Dhaka.

${ }^{4}$ Dr. A M Ashraful Anam, Associate Professor, Dhaka Community Medical College, Moghbazar, Dhaka

Correspondence: Dr. Fatema Binta Islam, Phone: +8801711240008 Email:fatema156@yahoo.com 


\section{INTRODUCTION:}

The link between pregnancy and thyroid is known since ages. It is now well established that not only overt but also subclinical thyroid dysfunction can have adverse effects on fetal and maternal outcome.1,3 But debate over the significance of thyroid dysfunction in pregnancy, the efficacy and usefulness of screening for the condition and the impact of treatment on maternal and neonatal outcomes is being continued.

Thyroid diseases affect approximately $4-5 \%$ of all pregnancies. The adverse outcomes have been associated with both overt hypothyroidism (about $0.3-0.5 \%$ of pregnancies), as well as subclinical hypothyroidism (about 2-3\% of pregnancies). ${ }^{4}$ Although prevalence of hyperthyroidism in pregnancy is low, Graves' hyperthyroidism causes significant adverse effects on the mother (miscarriage, placenta abruption, preterm delivery, and pre-eclampsia) as well as on the fetus. ${ }^{5}$ Up to $5 \%$ of neonates of mothers with Graves' disease may have hyperthyroidism due to the transplacental passage of maternal stimulating thyrotropin receptor antibodies (TRAbs). ${ }^{6}$ Maternal hypothyroidism may also be associated with adverse fetal and obstetric outcomes as observed in hyperthyroidism, while premature birth, low birth-weight, increased neonatal respiratory distress, \& more admissions to the neonatal intensive care unit have been described in babies born to mothers with hypothyroidism.3,7 The detrimental effect of hypothyroidism during pregnancy is on fetal brain development. Proper maternal thyroid function is important to the developing fetal neurons, ${ }^{8}$ particularly in the $1^{\text {st }}$ trimester of pregnancy when the fetus is completely dependent on the mother for thyroid hormone. Pregnancy is viewed as a state in which a combination of events concurs to modify the normal thyroid status. The hypermetabolic state of normal pregnancy makes clinical assessment of thyroid function difficult and therefore thyroid function often needs biochemical evaluation. ${ }^{9}$
Bangladesh is known to be one hyperendemic zone for iodine deficiency. ${ }^{10}$ Goitre and other iodine deficiency disorder is very common in our country. A study by Begum ${ }^{11}$ showed prevalence of overt and subclinical hypothyroidism in Bangladeshi pregnant women to be $3 \%$ and $5 \%$ respectively and that of overt and subclinical hyperthyroidism $3.5 \%$ and $4 \%$ respectively. The data overall showing greater prevalence of thyroid disorders in our pregnant population than that in western countries. Furthermore, prevalence of thyroid diseases is found to be more in Asian-Indian population justifying routine thyroid screening in early antenatal period. ${ }^{12,13}$ In the national survey for Iodine Deficiency Disease in 1993 Yousuf et $\mathrm{al}^{14}$ showed that the incidence of cretinism in Bangladseh is $0.5-0.9 \%$, which is a cause of concern for the physicians. As congenital hypothyroidism is the commonest preventable cause of mental retardation, routine antenatal thyroid screening and timely intervention for thyroid disorders gives an opportunity of lowering the incidence of cretinism and other IDDs in children.

In view of the potential adverse outcomes associated with maternal thyroid disorders and the obvious benefits of treatment, some expert panels have suggested routine thyroid function screening in all pregnant women. ${ }^{15,16}$ However, the Endocrine Society of America's Clinical Practice Guideline. ${ }^{17}$ recommends a case finding approach where only women at high-risk for thyroid disorders are tested. Apparently, case finding would seem a reasonable approach in relation to economic and logistic factors, but there has been growing evidence that a substantial number of women with thyroid dysfunction would not be diagnosed with this approach. ${ }^{16}$ Although prospective randomized trials to substantiate the benefit of routine antenatal thyroid screening are very few, it's necessity to prevent adverse maternal and fetal outcomes cannot be ignored. The clinical and epidemiological evidences do not justify universal screening at the present time. So, this study is an attempt to find the prevalence of 
thyroid dysfunction in pregnancy and necessity of routine screening for thyroid dysfunction in early pregnancy in the context of our country.

\section{METHODS:}

This cross-sectional study was conducted on pregnant women attending in the Out-patient Department of Obstetrics and Gynaecology (for routine antenatal checkup), Bangabandhu Sheikh Mujib Medical University (BSMMU) Hospital, Dhaka over a period of 12 months from July 2012 to June 2013. Pregnant women up to 36 weeks of gestation with singleton pregnancy were included. Patients with diagnosed case of thyroid disease undergoing treatment, multifoetal gestation, known chronic diseases like hypertension, diabetes mellitus, chronic liver and renal disease, or receiving medication that might interfere with normal thyroid function e.g., steroid, iodine, radiocontrast materials, amiodarone, carbamazepine, salicylates, lithium, para-amino salicylic acid (PAS) etc. were excluded from the study. A total 246 pregnant women were consecutively included. After briefing the purpose and procedure of the study to the participating subjects, informed written consent was obtained from them and data were collected using a structured questionnaire (research instrument) containing all the variables of interest.

Short menstrual, obstetric, past medical, family and personal histories were noted. Brief physical examination was carried out with due consent from the participating subjects and maintaining adequate privacy. Then with aseptic precaution, $5 \mathrm{ml}$ venous blood was collected from the ante-cubital vein into a clean, dry test tube to avoid hemolysis and was allowed to clot. Collected samples were centrifuged at $3000 \mathrm{rpm}$ for 15 minutes and the separated serum was collected in another test tube. All serum samples were preserved in the laboratory refrigerator and were tested for TSH first and for FT4 when TSH level was found deranged. Serum TSH estimation was carried out by the Abbott AxSym System Auto-analyzer. It is the $3^{\text {rd }}$ generation TSH assay system based on Microparticle Enzyme Immunoassay (MEIA) Technology. Thyroid hormone reference ranges for non-pregnant women is not appropriate in pregnancy. ${ }^{18}$ According to American Thyroid Association (ATA) guidelines, 2011, trimester-specific reference ranges for TSH, as defined in populations with optimal iodine intake, should be applied and if trimester-specific reference ranges for TSH are not available in the laboratory, the following reference ranges are recommended: first trimester, $0.1-2.5 \mathrm{mIU} / \mathrm{L}$; second trimester, 0.2-3.0 mIU/L; third trimester, $0.3-3.0 \mathrm{mIU} / \mathrm{L} .{ }^{19}$

Data were processed and analyzed using SPSS (statistical package for the social science Inc., Chicago, Illinois USA, version 16.0. The test statistics used to analyze the data were Chi-square $\left(\chi^{2}\right)$ Test and Student's t-Test. Data presented on categorical scale were expressed as frequency and corresponding percentage and were compared between groups using Chi-square $\left(\chi^{2}\right)$ Test, while the data presented on continuous scale were expressed as mean \pm SD and were compared between groups using Student's t-Test. For all analytical tests, the level of significance was set at 0.05 and $p<0.05$ was considered significant.

\section{RESULTS:}

Majority $(80.1 \%)$ of the pregnant women were 20-30 years old. $8.5 \%$ were below 20 years and $11.4 \%$ were above 30 years old with mean age being $25.7 \pm 4.1$ years. House-wives formed the predominant occupation (73.6\%). In terms of education, secondary and higher secondary level educated women were predominant (57\%) followed by primary $(19.9 \%)$, graduate and higher level educated. Illiterates comprised only $6.1 \%$. Over half $(50.8 \%)$ belonged to middle class followed by lower middle (19.9\%), upper middle class $(16.3 \%)$ and poor (13\%). Obstetric characteristics of the women show that $42.3 \%$ were nulipara, $30.1 \%$ primipara and $27.6 \%$ multipara. About two-thirds (65.4\%) were multigravida and the rest primigravida. In terms 
of gestational age about one-quarter (24.8\%) were in the $1^{\text {st }}$ trimester, $30.9 \%$ in $2^{\text {nd }}$ trimester and $44.3 \%$ in their $3^{\text {rd }}$ trimester. Past obstetric history of the studied women revealed that $13.1 \%$ were subfertile, $16.3 \%$ had history of abortion and $4.1 \%$ had history of preterm delivery (Table I). Some of them had only one (28\%) and some had multiple obstetric risk factors (3\%) while there were some others who had none of the risk factors (69\%).

\begin{tabular}{|c|c|c|}
\hline $\begin{array}{l}\text { Demographic } \\
\text { characteristics }\end{array}$ & Frequency & Percentage \\
\hline \multicolumn{3}{|l|}{ Age $^{*}(y r s)$} \\
\hline$<20$ & 21 & 8.5 \\
\hline $20-30$ & 197 & 80.1 \\
\hline$>30$ & 28 & 11.4 \\
\hline \multicolumn{3}{|l|}{ Occupation } \\
\hline Service & 38 & 15.7 \\
\hline Business & 2 & 0.8 \\
\hline Housewife & 181 & 73.6 \\
\hline Others & 25 & 10.2 \\
\hline \multicolumn{3}{|l|}{ Education } \\
\hline Illiterate & 15 & 6.1 \\
\hline Primary & 49 & 19.9 \\
\hline Secondary \& higher secondary & 140 & 57.0 \\
\hline Graduate plus & 42 & 17.0 \\
\hline \multicolumn{3}{|l|}{ Socioeconomic status } \\
\hline Poor & 32 & 13.0 \\
\hline Lower middle & 49 & 19.9 \\
\hline Middle & 125 & 50.8 \\
\hline Upper middle & 40 & 16.3 \\
\hline \multicolumn{3}{|l|}{ Parity } \\
\hline Nulipara & 104 & 42.3 \\
\hline Primipara & 74 & 30.1 \\
\hline Multipara & 68 & 27.6 \\
\hline \multicolumn{3}{|l|}{ Gestational age } \\
\hline $1^{\text {st }}$ trimester (up to 12 weeks) & 61 & 24.8 \\
\hline $2^{\text {nd }}$ trimester (13-28 weeks) & 76 & 30.9 \\
\hline $3^{\text {rd }}$ trimester ( $29-36$ weeks) & 109 & 44.3 \\
\hline \multicolumn{3}{|l|}{ Past obstetric history } \\
\hline History of subfertility & 32 & 13.1 \\
\hline History of abortion & 40 & 16.3 \\
\hline History preterm delivery & 10 & 4.1 \\
\hline
\end{tabular}

*Mean age $=25.7 \pm 4.1$ (range: $17-37$ ) years. Mean gestational age $=(20.3 \pm 8.7)$ weeks.
Table II demonstrates that mean serum TSH level was $2.29 \pm 1.22 \mathrm{mIU} / \mathrm{L}$ (range=0.06-5.56 mIU/L) and the mean serum FT4 level was $9.41 \pm 3.49$ $\mathrm{pmol} / \mathrm{L}$ (range $=0.12-18.15 \mathrm{pmol} / \mathrm{L}$ ). Based on serum level of $\mathrm{TSH}$, the overall prevalence of hypothyroidism was $29.7 \%$ and that of hyperthyroidism was $1.2 \%$. Thus, a total of $30.9 \%$ pregnant women had abnormal thyroid function status and the rest (69.1\%) were euthyroid based on normal range of serum TSH in the $1^{\text {st }}, 2^{\text {nd }}$ and $3^{\text {rd }}$ trimesters of pregnancy (Table II). Of the hypothyroid cases (29.7\%), 28.1\% had subclinical hypothyroidism and $1.6 \%$ had overt hypothyroidism. All cases of hyperthyroidism were sub-clinically hyperthyroid. Fig. 1 shows distribution of thyroid status of the study subjects in different trimesters.

\begin{tabular}{|c|c|c|c|}
\hline $\begin{array}{l}\text { Thyroid } \\
\text { hormones profile }\end{array}$ & -requency & Percentage & $\begin{array}{c}\text { Mean } \pm \text { SD } \\
\text { (Range) }\end{array}$ \\
\hline \multicolumn{4}{|l|}{ Level of thyroid hormones } \\
\hline Serum TSH level $(n=246)$ & ) --- & --- & $\begin{array}{l}2.29 \pm 1.22 \\
(0.06-5.56)\end{array}$ \\
\hline Serum FT4 level $(n=71)$ & --- & --- & $\begin{array}{r}9.41 \pm 3.49 \\
(0.12-18.15)\end{array}$ \\
\hline
\end{tabular}

Thyroid function status

$\begin{array}{lcc}\text { Hypothyroidism } & 73 & 29.7 \\ \text { Euthyroidism } & 170 & 69.1 \\ \text { Hyperthyroidism } & 3 & 1.2\end{array}$

Table III shows that the studied pregnant women with abnormal thyroid status were a bit older than their euthyroid counterparts $(p=0.039)$. Socioeconomic status and occupation of the pregnant women were not found to be associated with thyroid function status $(p=0.146 \& p=0.053$ respectively). Pregnant women who had a past history thyroid disease exhibited a higher prevalence of abnormal thyroid function than those who did not have such history $(p=0.041)$. Positive family history of thyroid disease was found to be associated with of thyroid disorder $(p=0.017)$. 


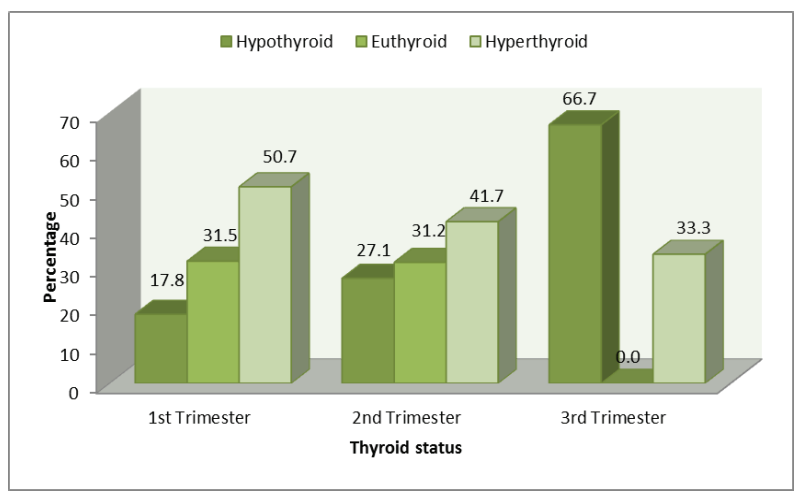

Fig. 1: Distribution of thyroid status of the study subjects in different trimesters

\begin{tabular}{|c|c|c|c|}
\hline \multicolumn{4}{|c|}{$\begin{array}{l}\text { Table III. Association of thyroid function status with } \\
\text { demographic features \& family history }\end{array}$} \\
\hline \multirow{2}{*}{$\begin{array}{l}\text { Demographic } \\
\text { characteristics }\end{array}$} & \multicolumn{2}{|c|}{ Thyroid function } & \multirow[b]{2}{*}{ p-value } \\
\hline & $\begin{array}{l}\text { Dysfunction } \\
(n=76)\end{array}$ & $\begin{array}{l}\text { Euthyroid } \\
(\mathrm{n}=170)\end{array}$ & \\
\hline Age* $^{*}$ (yrs) & $26.5 \pm 4.1$ & $25.3 \pm 4.1$ & 0.039 \\
\hline \multicolumn{4}{|l|}{ Socioeconomic status\# } \\
\hline Poor and middle class & $54(71.1)$ & $152(89.4)$ & \multirow{2}{*}{0.146} \\
\hline Upper class & $22(28.9)$ & 18 (10.6) & \\
\hline \multicolumn{4}{|l|}{ Occupation\# } \\
\hline Service $\&$ business & $9(11.8)$ & $31(18.3)$ & \multirow{2}{*}{0.053} \\
\hline Housewife \& others & $67(88.2)$ & $139(81.7)$ & \\
\hline \multicolumn{4}{|c|}{ Past history thyroid disease\# } \\
\hline Yes & $7(9.2)$ & $5(2.9)$ & \multirow{2}{*}{0.041} \\
\hline No & $69(90.8)$ & $165(97.1)$ & \\
\hline \multicolumn{4}{|c|}{ Family history of thyroid disease\# } \\
\hline Yes & $8(10.5)$ & $3(1.8)$ & \multirow{2}{*}{0.017} \\
\hline No & $68(89.5)$ & $167(98.2)$ & \\
\hline
\end{tabular}

*Data were analysed using Unpaired t-Test and were presented as mean $\pm \mathrm{SD}$.

\# Data were analysed using $\chi^{2}$ Test; figures in the parentheses denote corresponding percentage.

Pregnant women with a previous history of irregular menstruation were more often prone to be associated with abnormal thyroid function during pregnancy $(26.3 \%)$ compared to those having regular menstruation $(15.9 \%)(p=0.042)$. Visible goiter demonstrated their significant presence $(34.2 \%)$ in pregnant women with thyroid dysfunction as compared to euthyroid pregnant women $(15.3 \%)(p=0.001)$ (Table IV).

\begin{tabular}{|c|c|c|c|}
\hline \multirow[b]{2}{*}{ Variables } & \multicolumn{2}{|c|}{ Thyroid function } & \multirow[b]{2}{*}{$\mathrm{p}$-value } \\
\hline & $\begin{array}{l}\text { Dysfunction } \\
(n=76)\end{array}$ & $\begin{array}{c}\text { Euthyroid } \\
(n=170)\end{array}$ & \\
\hline \multicolumn{4}{|c|}{ Menstrual history } \\
\hline Irregular & $20(26.3)$ & 27 (15.9) & \multirow{2}{*}{0.042} \\
\hline Regular & $56(73.7)$ & $143(84.1)$ & \\
\hline \multicolumn{4}{|c|}{ Visible goitre } \\
\hline Present & $26(34.2)$ & $26(15.3)$ & \multirow{2}{*}{0.001} \\
\hline Absent & $50(65.8)$ & $144(84.7)$ & \\
\hline
\end{tabular}

*Data were analysed using Chi-squared $\left(\chi^{2}\right)$ Test.

Figures in the parentheses denote corresponding percentage.

Nullipara and multipara women were more prone to be associated with abnormal thyroid function than their primipara counterparts $(p=0.025)$. Gestational age was not found as the determinant of thyroid function $(p=0.377)$. Of the past obstetric events, past history of subfertility and abortion were significantly associated with abnormal thyroid function in the current pregnancy ( $p=0.004$ and $p<0.001$ respectively) (Table $\mathrm{V}$ ).

Table V. Association between obstetric characteristics and thyroid function status

\begin{tabular}{lccc} 
& \multicolumn{2}{c}{ Thyroid function } & \\
\cline { 2 - 3 } $\begin{array}{l}\text { Obstetric } \\
\text { characteristics }\end{array}$ & $\begin{array}{c}\text { Dysfunction } \\
(\mathrm{n}=76)\end{array}$ & $\begin{array}{c}\text { Euthyroid } \\
(\mathrm{n}=170)\end{array}$ & $\mathrm{p}$-value \\
Parity & $36(47.4)$ & $68(40.0)$ & \\
$\quad$ Nullipara & $14(18.4)$ & $60(35.3)$ & 0.025 \\
Primipara & $26(34.2)$ & $42(24.7)$ & \\
Multipara & & & \\
Gestational age & $15(19.7)$ & $46(27.1)$ & \\
$1^{\text {st }}$ trimester (up to 12 weeks) & & \\
$2^{\text {nd }}$ trimester (13-28 weeks) & $23(30.3)$ & $53(31.2)$ & 0.377 \\
$3^{\text {rd }}$ trimester (29-36 weeks) & $38(50.0)$ & $71(41.8)$ & \\
Past history of subfertility & & & \\
Present & $17(22.4)$ & $15(8.9)$ & 0.004 \\
Absent & $59(77.6)$ & $155(91.1)$ & \\
Past history of abortion & & & \\
Present & $22(28.9)$ & $18(10.6)$ & $<0.001$ \\
Absent & $54(71.1)$ & $152(89.4)$ & \\
Past history of preterm delivery & & & \\
Present & $3(3.9)$ & $7(4.1)$ & 0.627 \\
Absent & $73(96.1)$ & $163(95.9)$ & \\
& & &
\end{tabular}

*Data were analysed using Chi-squared $\left(\chi^{2}\right)$ Test.

Figures in the parentheses denote corresponding percentage. 
Although, gestational age was not found as the significant determinant of thyroid function $(p=0.377)$, it was found that hypothyroid state was fairly common with advancing gestation $\left(21.3 \%, 30.3 \%\right.$ and $34 \%$ in the $1^{\text {st }}, 2^{\text {nd }}$, and $3^{\text {rd }}$, trimesters respectively). On the contrary, hyperthyroid cases were mainly confined to $1^{\text {st }}$ trimester only (Fig 2).

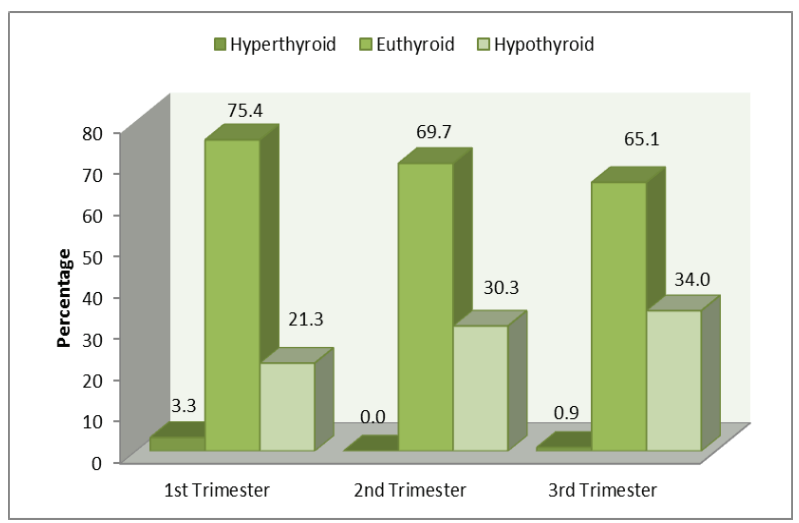

Fig. 2: Gestational age-wise distribution of thyroid disorders among the study subjects

\begin{tabular}{l}
$\begin{array}{l}\text { Table VI. Association between presence of risk factors and } \\
\text { thyroid status }\end{array}$ \\
$\begin{array}{lllll}\text { Risk factors } & \\
& \begin{array}{c}\text { Thyroid function } \\
(n=76)\end{array} & \begin{array}{c}\text { Euthyroid } \\
(n=170)\end{array} & \text { p-value } & \begin{array}{c}\text { Odds Ratio } \\
\text { (95\% Cl of OR) }\end{array} \\
\text { Present } & 55(72.4) & 72(42.4) & & \\
\text { Absent } & 21(27.6) & 98(57.6) & & 3.6(1.9-6.4)\end{array}$ \\
\hline
\end{tabular}

*Data were analysed using Chi-squared $\left(\chi^{2}\right)$ Test.

Figures in the parentheses denote corresponding percentage.

Of the 7 risk factors studied, nearly half (48.4\%) of the patients did not have any risk factor, $27.2 \%$ had single risk factor, $18.7 \%$ two risk factors and $5.7 \%$ more than two risk factors. The risk of developing abnormal thyroid function was observed to be 3.6(95\% CI=1.9-6.4) times higher in those who had at least one risk factor than those who did not have any risk factor $(p<0.001)$ (Table VI).

\section{DISCUSSION:}

Maternal thyroid function is known to alter during pregnancy and an increased need of thyroid hormones in gestation may predispose those with underlying thyroid disturbances (e.g. chronic autoimmune thyroiditis) to hypothyroidism. ${ }^{20}$ Thyroid dysfunction may be associated with several adverse pregnancy outcomes including perinatal, neonatal outcomes and later possibly affect maternal and child health as well. ${ }^{17}$ These associations can only be confirmed or discarded by means of high-quality population-based studies with sufficient follow-up data. So, authentic data are crucial when deciding whether pregnant women should be screened for thyroid dysfunction.

In the present study about two-thirds (65.4\%) of the patients were multigravida with majority $(44.3 \%)$ in their $3^{\text {rd }}$ trimester. Past history of preterm delivery was present in only $4.1 \%$ cases, whereas past history of sub-fertility and abortion were not less ( $13.1 \%$ and $16.3 \%$ respectively). This might be because BSMMU is a referral hospital, so women having any past bad obstetric event come to this hospital for better management. Based on normal range of serum $\mathrm{TSH}$ in the $1^{\text {st }}, 2^{\text {nd }}$ and $3^{\text {rd }}$ trimesters of pregnancy, ${ }^{19}$ 76(30.9\%) had thyroid dysfunction (29.7\% hypothyroid \& $1.2 \%$ hyperthyroid). After applying conventional non-pregnant range of serum TSH, that is, 0.4-4.0 $\mathrm{mIU} / \mathrm{l}$ in our study, thyroid dysfunction cases fall to almost half (15.4\%). Out of 76 women, 71 were subjected to test for FT4; $4(1.6 \%)$ of them were found to have low FT4. Thus, a total of $28.1 \%$ were subclinically hypothyroid and $1.6 \%$ were overt hypothyroid. Of the hypothyroid cases, about half $(50.7 \%)$ were in $3^{\text {rd }}$ trimester and rest $17.8 \%$ and $31.5 \%$ were in $1^{\text {st }}$ and $2^{\text {nd }}$ trimesters respectively.

The present study showed a much higher proportion (29.7\%) of hypothyroidism, compared to other studies. Sahu and associates ${ }^{21}$ showed subclinical hypothyroidism in $6.5 \%$ and overt hypothyroidism in $4.6 \%$ cases. Goel and associates ${ }^{12}$ showed overall prevalence of hypothyroidism to be $6.3 \%$ (overt $2.9 \%$ and subclinical $3.4 \%$ ). In a study in Poland, $10.4 \%$ of the pregnant women screened for thyroid dysfunction in their $1^{\text {st }}$ trimester exhibited hypothyroidism. ${ }^{22}$ Spong ${ }^{23}$ in a study of screening for subclinical hypothyroidism in 
pregnant women demonstrated a much lower prevalence of hypothyroid status (2.5\%). Maternal hypothyroidism affects between $0.19-2.5 \%$ pregnancies depending on race and geographic locations. ${ }^{24}$ In a similar study conducted in Bangladesh by Begum, ${ }^{11}$ clinical and subclinical hypothyroidism together formed $8 \%$ of the pregnant women, which is well below the findings of the present study. In contrast, Casey et $\mathrm{al}^{3}$ showed $2.3 \%$ subclinical hypothyroidism, but when a narrower TSH reference range (0.4-2.5 $\mathrm{mIU} / \mathrm{mL}$ ) was applied to the data, the prevalence of abnormal TSH increased to $14.9 \%$. Weiwei ${ }^{13}$ showed significantly higher prevalence of hypothyroidism in both high-risk group and non-high-risk group (10.9\% vs. $7.0 \%)$. Findings of both the studies are closer to our findings. Besides, there are slight but significant differences in serum TSH concentrations with respect to ethnic group which should also be taken into account while screening for thyroid hormones in pregnant women. Black and Asian women have TSH values that are on an average $0.4 \mathrm{mIU} / \mathrm{L}$ lower than in white women which may persist during pregnancy. ${ }^{25,26}$ Pregnant women of Moroccan, Turkish, or Surinamese descent residing in the Netherlands, possess TSH levels $(0.2-0.3 \mathrm{mIU} / \mathrm{L})$ lower than Dutch women throughout pregnancy. ${ }^{27}$ Moreover, TSH ranges vary depending on differences between methods of analysis. ${ }^{28}$ The study by Sakinah ${ }^{29}$ showed more prevalence of goiter and hypothyroidism in Indians than in other races, which supports our findings.

The higher prevalence of subclinical hypothyroidism in our study may be due to proportionately higher number of patients in the $2^{\text {nd }}$ and $3^{\text {rd }}$ trimesters of pregnancy as because level of TSH increases with the advance of pregnancy. ${ }^{30}$ Moreover, as Bangladesh is an endemic zone for iodine deficiency, ${ }^{14}$ it may have contributed to the higher prevalence of thyroid dysfunction in our population. Adoption of gestation specific narrow reference range of serum TSH according to ATA guidelines, 2011 in our study, may be the main reason behind this high prevalence of hypothyroid cases.
Only $1.2 \%$ of patients exhibited subclinical hyperthyroidism which is quite close to the finding of Feki et al $(1.3 \%)^{31}$ and Weiwei et al $(2.7 \%)^{13}$. Whereas study by Begum (2004) showed much higher prevalence of hyperthyroidism (subclinical $4 \%$ and overt $3.5 \%$ ) which may be due to other autoimmune diseases or excessive iodine intake or due to transient pregnancy induced thyrotoxicosis as the author explained. In our study, hyperthyroid cases were mainly found in $1^{\text {st }}$ trimester $(66.7 \%)$, which may reflect $\beta$-hCG induced transient thyrotoxicosis or flare up of previously present subclinical hyperthyroidism. However, as we have not estimated serum $\beta$ hCG, these cases cannot be certainly diagnosed as having transient gestational thyrotoxicosis.

The present study showed that older pregnant women were more often associated with thyroid dysfunction ( $p=0.039)$, which is in agreement with study by Elizabeth et al. ${ }^{32}$ Pregnant women with abnormal thyroid function was on an average of 1.2 years older than those with euthyroid status. Bocos-Terraz and colleagues ${ }^{33}$ reported significant differences in serum TSH in terms of age of the mother $(p<0.005)$. It was observed that TSH level during the first few gestational weeks was lower than the subsequent weeks and hypothyroid state was fairly common with advancing gestation $(21.3 \%, 30.3 \%$ and $34 \%$ in the $1^{\text {st }}, 2^{\text {nd }}$, and $3^{\text {rd }}$, trimesters respectively). But as we did not measure TSH in all three trimesters in same patients, it cannot be emphasized that advancing gestational age is a significant determinant of thyroid dysfunction. Kumar and associates $^{30}$ found that mean T4 levels began to rise from $164.5 \mathrm{nmol} / \mathrm{L}$ in the first trimester to

$165.8 \mathrm{nmol} / \mathrm{L}$ in the second trimester and then decreased in the third trimester to $159.9 \mathrm{nmol} / \mathrm{L}$; they reported mean TSH level to rise progressively through the three trimesters of pregnancy from 1.20 microlU/ $\mathrm{ml}$ in the $1^{\text {st }}$ trimester to 2.12 $\mathrm{microlU} / \mathrm{ml}$ in the $2^{\text {nd }}$ trimester and further to 3.30 $\mathrm{microlU} / \mathrm{ml}$ in the $3^{\text {rd }}$ trimester of pregnancy which is quite consistent with findings of the present study. Pregnant women who had personal (4.9\%) 
or family history $(3.3 \%)$ of thyroid disease in the past exhibited a higher prevalence of abnormal thyroid function than those who did not have such history ( $p=0.041 ; p=0.044$ respectively). Previous menstrual irregularity, past history of subfertility or abortion were significantly associated with thyroid disorders.

Presence of goitre in the current pregnancy also showed significant association with thyroid dysfunction. The higher prevalence of goitre in this cohort may be attributed to compensatory adaptation of thyroid gland to meet the increased demand for thyroid hormones during pregnancy. Khandakar ${ }^{34}$ in Dhaka city reported an even higher prevalence of goiter in pregnant women (34.2\%). The study concluded that although goiter was present in a considerable number of pregnant women, they were in euthyroid status as observed by increased production of serum total thyroxin (T4) by thyroid to fulfill the maternal requirement, with nearly unchanged $\Pi T 3$ and $\mathrm{TSH}$ secretion. The present study showed that the risk of having thyroid dysfunction is more than $3(95 \%$ $\mathrm{CI}=1.9$ - 6.4) times higher in those who had at least one risk factor (out of 7 risk factors) than those who did not have any risk factors. However, over one-quarter (27.6\%) of pregnant women without any risk factors developed abnormal thyroid function suggesting that risk factor-based screening for thyroid disorders may miss a substantial number of cases with thyroid dysfunction. This finding of our study is consistent with that of study by Vaidya et al. ${ }^{16}$ in which they screened 1560 consecutive pregnant women. They classified $413(26.5 \%)$ women who had personal history of thyroid or other autoimmune disorder or a family history of thyroid disorder as a high-risk group. They examined whether testing only such high-risk group would pick up most pregnant women with thyroid dysfunction. The results were forty women $(2.6 \%)$ had raised TSH ( $>4.2 \mathrm{IU} / \mathrm{ml}$ ). The prevalence of raised TSH was higher in the high-risk group than that in low risk-group [6.8 vs. $1 \%, 95 \%$ confidence interval $(C I)=3.3-12.6 p<0.0001)]$. However, 12 of 40 women with raised TSH (30\%) were in the low-risk group. The study concluded that targeted thyroid function testing of only high-risk group would miss about $1 / 3^{\text {rd }}$ of pregnant women with overt or subclinical hypothyroidism.

Overall, it is evident that prevalence of thyroid disorders is more or less common in pregnant women. The disorder is primarily hypothyroidism and rarely hyperthyroidism. The high prevalence of thyroid disorder in Begum's ${ }^{11}$ study and even higher prevalence in the present study suggest that Bangladesh is an endemic zone, and pregnant women are at much higher risk of developing thyroid disorders.

\section{CONCLUSION:}

The study concluded that one in every three pregnant women may have thyroid disorders, primarily subclinical hypothyroidism. Older women with personal and family history of thyroid disorders, past menstrual irregularity and obstetric characteristics like multiparity, history of subfertility or abortion had more than 3 times higher risk of developing thyroid dysfunction than the pregnant women without having these features. More than one-quarter of the thyroid dysfunction cases did not have any risk factor. These patients would have been otherwise remained undiagnosed if risk factor-based thyroid screening was done. So, screening for thyroid disorders in pregnancy should be routinely done.

\section{REFERENCES:}

1. Allan WC, Haddow JE, Palomaki GE, Williams JR, Mitchell ML, Hermos RJ et al. Maternal thyroid deficiency and pregnancy complications: implications for population screening. J Med Screen 2000;7:127-30.

2. Pop VJ, Brouwers EP, Wijnen H, Oei G, Essed GG \& Vader $\mathrm{HL}$. Low concentrations of maternal thyroxin during early gestation: a risk factor of breech presentation? BJOG 2004;111(9):925-30.

3. Casey BM, Dashe JS, Wells CE, McIntire DD, Byrd W, Leveno KJ et al. Subclinical hypothyroidism and pregnancy outcomes. Obstet Gynecol 2005;105:239-45.

4. Klein RZ, Haddow JE, Faix JD, Brown RS, Hermos RJ, Pulkkinen et al. Prevalence of thyroid deficiency in pregnant women. Clin Endocrinol 1991;35(1):41-6. 
5. Marx $\mathrm{H}$, Amin $\mathrm{P}$ and Lazarus $\mathrm{JH}$. Pregnancy plus: hyperthyroidism and pregnancy. BMJ 2008;336:663-7.

6. Patil-Sisodia K, Mestman JH. Graves hyperthyroidism and pregnancy: a clinical update. Endocrine Practice 2010;16(1):118-29.

7. Negro R. Thyroid insufficiency during pregnancy: complications and implications for screening. Expert Rev Endocrinol Metab 2008;3(2):137-46.

8. Williams GR. Neurodevelopmental and neurophysiological actions of thyroid hormone. J Neuroendocrinol 2008; 20(6):784-94.

9. Ballabio M, Poshyachinda M, Ekins RP. Pregnancyinduced changes in thyroid function: role of human chorionic gonadotropin as putative regulator of maternal thyroid. J Clin Endocrinol Metab 1991;73:824-31.

10. WHO. Iodine status worldwide: WHO Global Database on Iodine Deficiency. Geneva, Department of Nutrition for Health and Development, World Health Organization. 2004.

11. Begum SA. Routine screening of thyroid function in early pregnancy. BSMMU, Dhaka, 2004.

12. Goel P, Kaur J, Saha PK, Tandon R \& Devi L. Prevalence, associated risk factors and effects of hypothyroidism in pregnancy: a study from north India. Gynecol Obstet Invest 2012;74(2):89-94.

13. Weiwei W, Weiping T, Zhongyan S, Sen W, Li J, Zhu L et al. The prevalence of thyroid disorders during early pregnancy in China: the benefits of universal screening in the first trimester of pregnancy. European Journal of Endocrinology 2011;164:263-68.

14. Yousuf HKM, Salamatullah $Q$, Islam MN, Hoque $T$, Baguer M, Pandav S. Report of Iodine deficiency disorder survey in Bangladesh. Dhaka, UNICEF, 2003.

15. Gharib H, Tuttle RM, Baskin J, Fish LH, Singer PA, McDermott MT. Subclinical thyroid dysfunction: a joint statement on management from the American Association of Clinical Endocrinologists, the American Thyroid Association, and The Endocrine Society. Thyroid 2005; 15:24-8.

16. Vaidya B, Anthony S, Bilous M, Shields B, Drury J, Hutchison $S$ et al. Detection of thyroid dysfunction in early pregnancy: universal screening or targeted high-risk case finding. J Clin Endocrinol Metab 2007;92:203-7.

17. Abalovich M, Amino N, Barbour LA, Cobin RH, De Groot LJ, Glinoer $D$ et al. Clinical practice guideline: management of thyroid dysfunction during pregnancy and postpartum: an endocrine society clinical practice guideline. J Clin Endocrinol \& Metab 2007;92(suppl. 8):S1-47.
18. Stagnaro-Green A, Abalovich M, Alexander E, Azizi $F_{\text {, }}$ Mestman J, Negro R et al. Guidelines of the American Thyroid Association for the Diagnosis and Management of Thyroid Disease During Pregnancy and Postpartum. 2011;21(10):1081-1125.

19. ATA. Guidelines of the American Thyroid Association for the Diagnosis and Management of Thyroid Disease During Pregnancy and Postpartum. Thyroid Mary Ann Liebert Inc 2011;21(10):1109.

20. Davis LE, Leveno KJ and Cunningham FG. Hypothyroidism complicating pregnancy. Obstetrics and Gynecology 1988;72(1):108-12.

21. Sahu MT, Das V, Mittal S, Sahu M. Overt and subclinical thyroid dysfunction among Indian pregnant women and it's effect on maternal and fetal outcome. Arch gynecol Obstetr 2010;281(2):215-20.

22. Matuszek B, Zakościelna K, Baszak-Radomańska $E_{\text {, }}$ Pyzik A, Nowakowski A. Universal screening as a recommendation for thyroid tests in pregnant women. Annals of Agricultural and Environmental Medicine 2011;18(2):375-79.

23. Spong CY. Subclinical hypothyroidism: should all pregnant women be screened. Obstet \& Gynaecol 2005; 105:235-36.

24. Montoro MN. Management of hypothyroidism during pregnancy. Clin Obstet Gynecol 1997;40:65-80.

25. Price A, Obel O, Cresswell J, Catch I, Rutter S, Barik S et al. Comparison of thyroid function in pregnant and non-pregnant Asian and western Caucasian women. Clin Chim Acta 2001;308(1-2):91-8.

26. Walker JA, Illions EH, Huddleston JF, Smallridge RC. Racial comparisons of thyroid function and autoimmunity during pregnancy and the postpartum period. Obstet Gynecol 2005;106:1365-71.

27. Benhadi N, Wiersinga WM, Reitsma JB, Vrijkotte TG, van der Wal MF et al. Ethnic differences in TSH but not in free T4 concentrations or TPO antibodies during pregnancy. Clin Endocrinol (Oxf) 2007;66:765-70.

28. Thienpont LM, Van UK, Beastall G, Faix JD, Ieiri T, Miller WG. IFCC Working Group on Standardization of Thyroid Function Tests 2010: Report of the IFCC Working Group for Standardization of Thyroid Function Tests; part 1: thyroid-stimulating hormone. Clin Chem 2010;56: 902-11.

29. Sakinah SO, Khalid BA, Aishah AB. Racial disparity in the prevalence of thyroid disorder during pregnancy. Ann Acad Med Singapore 1993;22(4): 563-6. 
30. Kumar A, Gupta N, Nath T, Sharma JB \& Sharma S. Thyroid function tests in pregnancy. Ind J Med Sci 2003; 57(6):252-58.

31. Feki M, Menif S, Tanfous N, Zouari H, Kaabachi $\mathrm{H}$. Thyroid disorders in pregnancy: Frequency and association with selected diseases and obstetrical complications in Tunisian women. Clinical Biochemistry 2008;41:927-31.

32. Elizabeth N, Oken E, Matthew W, Gillman M, Lee SL, Magnani $B$, et al. Association of First-trimester Thyroid Function Test Values With Thyroperoxidase Antibody Status, Smoking, and Multivitamin Use. Endocrine Practice 2008;14(1):33-39.
33. Bocos-Terraz JP, Izquierdo-Alvarez $\mathrm{S}$, Bancalero-Flores JL, Alvarez-Lahuerta R, Aznar-Sauca A, Real-Lopez E et al. Thyroid hormones according to gestational age in pregnant Spanish women. BMC Res Notes 2009;2:237.

34. Khandakar MA, Ali MS, Kahtun M. Thyroid status of normal pregnant women in Dhaka City. MMJ 2002;11(1):1-5. 